\title{
User satisfaction with the Family Health Program in Vespasiano, Minas Gerais, Brazil
}

\author{
Katherine E. Mues, ${ }^{1}$ Joana C. Resende, ${ }^{1}$ Otávio C. dos Santos, ${ }^{2}$ \\ Lilian G. Perez, ${ }^{1}$ José A. Ferreira, ${ }^{2}$ and Juan S. Leon ${ }^{1}$
}

Suggested citation

Mues KE, Resende JC, dos Santos OC, Perez LG, Ferreira JA, Leon JS. User satisfaction with the Family Health Program in Vespasiano, Minas Gerais, Brazil. Rev Panam Salud Publica. 2012;31(6):454-60.

ABSTRACT Objective. To assess factors influencing perspectives on Brazil's national Family Health Program (PSF) by exploring satisfaction with PSF units and home-visit community health agents and perceptions about PSF unit accessibility among frequent users (primary caretakers of children under age 5) in Vespasiano, Minas Gerais.

Methods. Data were collected though cross-sectional household surveys to determine programmatic and demographic factors affecting user satisfaction with the PSF. Multivariate logistic modeling was used to estimate users' satisfaction with PSF units and agents and perceived access to PSF unit services. Chi-square and analysis of variance (ANOVA) tests were used to estimate statistical differences.

Results. The majority of caretakers were satisfied with both their PSF unit and their PSF community health agent and had received at least one monthly home visit from the health agent. Satisfaction with both the health agent and the unit was positively associated with perceived access to the unit and frequency of agent home visits. Caretakers who reported that their PSF agent made one or more home visits per month were more likely to perceive the PSF unit as being "accessible" (or "sometimes accessible").

Conclusions. The current data are important indicators of population health in Minas Gerais, Brazil, and suggest that users' satisfaction with the PSF and perceptions about its accessibility can be improved by ensuring that all households receive at least one health agent home visit per month. These results could be applied to other parts of Brazil or Latin America to improve understanding of user perceptions of health systems.

Key words Program evaluation; national health programs; child welfare; patient satisfaction; diarrhea, infantile; rotavirus vaccines; Brazil.

Health system evaluations are a key indicator of the health status of both a country's aggregate population and its various sub-populations. Population health is often assessed based on the estimated quality and outcomes of a health system and/or the number of people reached (1). User perceptions and satisfaction are also indicators of

\footnotetext{
Rollins School of Public Health, Emory University, Atlanta, Georgia, United States of America. Send correspondence to: Juan S. Leon, juan.leon@emory.edu

2 Faculdade da Saúde e Ecologia Humana (FASEH), Vespasiano, Minas Gerais, Brazil
}

health system effectiveness and are thus essential aspects of health care quality research (2-4), and may be correlated to other indicators of quality of care (5-7).

Brazil's Family Health Program (Programa de Saúde da Familia, PSF) is a national community-based primary health care strategy that has changed the model for Brazilian universal coverage from a tertiary care system to one focused on prevention through primary care (8) while providing pathways to other levels of care. The PSF is one arm of Brazil's Unified Health System (Sistema Único de
Saúde, SUS), the public health care subsystem implemented in 1988. The SUS also includes oral health care, ambulatory services, emergency care services, HIV / AIDS treatment programs, workers' health services, and a network of hospital and tertiary care centers. The SUS and PSF are available to all Brazilians, regardless of their insurance or occupational status. Prior to the implementation of the SUS, Brazilian health care was delivered through either the private sector or the public social security system, depending on occupational status (8). 
The PSF focuses on primary health care, disease prevention, and health promotion, and is carried out through decentralized teams working out of local, community-based units. Each team includes one family doctor, one nurse, one nurse assistant, and six community health agents, and covers an average of 3000 inhabitants (9). Since its implementation in 1994, the PSF has grown to 30328 teams covering 50.7\% of Brazil's population (based on 2009 estimates). The long-term goal of the program is universal coverage (10). The growth of the PSF coincided with (11-14) a decrease in child and infant mortality rates and was ultimately associated with it (12-14).

Individual users' perspectives should be studied to improve health systems $(15,16)$, especially those of caretakers for children under 5 years old, who frequently use health systems for their vulnerable children. To date, limited research has been conducted on the perceptions and satisfaction of caretakers of children served by the PSF. Some evaluations indicate that users are satisfied with the program and have a strong relationship with the PSF staff and programs, as well as a positive perception of their child's health status (17), and consider PSF community health agents as the most outstanding health professionals (18). However, few studies have addressed the question of how demographic and programmatic factors are collectively associated with these perspectives, and to the best of the authors' knowledge no population-level analyses of these variables have been conducted using multivariate analysis.

To address these gaps, the current study assessed factors that influence the perspectives of users (primary caretakers of children younger than 5 years and covered by the PSF) in Vespasiano, Minas Gerais State, Brazil. Minas Gerais was selected for study because it ranks among the highest for number of PSF health teams and PSF coverage (19). The municipality of Vespasiano was chosen because its entire PSF system could be sampled logistically, and the current authors' research partners at Vespasiano's Medical School (Faculdade da Saúde e Ecologia Humana, FASEH) had relationships with and worked alongside its PSF team. The study explored user satisfaction with PSF units and PSF community health agents, and user perceptions about PSF unit accessibility.
In a sub-analysis, the authors examined use of and satisfaction with PSF diarrhea care and prevention services (one of the focuses of the program) among primary caretakers of children under 5 years old. The results of the study could 1) help inform Brazilian policy makers about key aspects of the PSF, 2) contribute to the field of health care quality research, and 3) provide insight on the use of perceptions as indicators of population health in Latin America.

\section{MATERIALS AND METHODS}

In this cross-sectional study, primary caretakers of children younger than age 5 and covered by the PSF in the municipality of Vespasiano in Minas Gerais were interviewed from June through August 2009 by students from the FASEH who were not affiliated with the PSF. Surveys were conducted in all 10 of the PSF unit coverage areas in Vespasiano. Lists of all households with at least one child 5 years or younger and covered by the PSF were provided by each PSF unit. A total of 310 out of 2101 households were selected using proportionally allocated stratified random sampling (stratified by PSF unit). Caretakers had to be at least 18 years of age to be included in the sample. Approval of human research ethics for the study was granted by institutional review boards at Emory University and FASEH.

Although the sample size was originally calculated to obtain a precision of 0.05 around an estimated prevalence of $50 \%$ user satisfaction with both the PSF unit and the PSF community health agents, inaccuracies in the original sampling frame and failure to apply a fractional sampling interval when selecting households resulted in an actual sample size of 310 households, which had a precision of 0.055 . Of those 310 households, contact was made at 292 of them (94\%) and 253 households ultimately agreed to participate, resulting in an $82 \%$ response rate. Surveys were conducted in Portuguese in the caretakers' home or place of work.

The study questions, which were developed independently by the authors based on validated surveys (20), collected information on demographics, general perceptions of the PSF unit and the PSF agent, diarrhea prevalence in last two weeks, perceptions of diarrhea care and prevention from the PSF unit and the PSF agent, and knowledge about and coverage of the rotavirus vaccine, among other topics.

The outcome variables of interestsatisfaction with the PSF unit and the PSF agent, and perceived access to the PSF unit-were collected through the questions "How satisfied are you with services provided at the PSF unit?" and "How satisfied are you with the advice and services provided by your community agent during home visits?" Participants were given the following response options: "very satisfied," "satisfied," "neither satisfied nor dissatisfied," "dissatisfied," and "very dissatisfied." The outcome was dichotomized into "satisfied" or "dissatisfied or neither" in statistical analyses. In addition, participants were asked the question "Are the health care services at the PSF unit easy to access?" (with "always," "sometimes," and "never" provided as possible responses). The exposure of interest-frequency of PSF agent home visits-was also collected through self-report in response to the question "How often does your community agent come to your household?" (with "never," "less than once per month," "once per month," and "more than once per month" provided as possible responses).

Interviewers used the Brazilian government's child health handbook (Caderneta de Saúde da Criança), which includes vaccination documentation, to verify if all eligible children ${ }^{3}$ in the household had received a complete dose (at 2 and 4 months ${ }^{4}$ ) of the rotavirus vaccination (Rotarix ${ }^{\circledR}$, introduced in Brazil in March 2006) (21).

Statistical analysis was completed using SAS statistical package version 9.2 (SAS Institute, Cary, NC, USA) and complex sample design analysis methods (22). Weights were calculated and applied to observations from each PSF unit to account for oversampling and under-sampling in some PSF units, and eligibility and response rates. A significance level of $P<0.05$ was used, based on chi-square $\left(\chi^{2}\right)$ and analysis of variance (ANOVA) tests, and multivariate logistic modeling was conducted. After assessing colinearity, all potential inter-

\footnotetext{
3 Those born after 1 November 2005 who were at least 16 weeks old at the date of the interview and had their first vaccine dose at least 8 weeks prior to the interview.

4 The minimum age to receive the first dose of the vaccine is 6 weeks; the maximum age to receive the second dose is 24 weeks.
} 
action terms and available demographic confounders (age, education, income, household number of children under age 5, and length of commute from caretaker's house to the PSF unit) were considered in building the model. The final models were chosen after considering both a priori and data-driven (odds ratio [OR] within $10 \%$ of the gold standard) confounding criteria (23).

\section{RESULTS}

\section{Population}

Based on the self-reported data, most primary caretakers of children younger than 5 years old were female, married or living with a partner, and mothers or grandmothers of children in the household, with a low education level, and regular employment status (Table 1). The median age of the caretakers was 34 years, and the median monthly income for the 200 households reporting regular employment was 785 Brazilian reais (BRL) or about US\$ 398 (based on the July 2009 exchange rate of 1 USD per 1.97 BRL (24)).

\section{Community perceptions of PSF units and PSF health agents}

To understand the general community perception of the PSF, caretakers were asked about their overall satisfaction with all services provided both by the PSF agent and the PSF unit, and how they perceived their accessibility to the PSF unit. Most caretakers of young children were satisfied with both their PSF unit and their PSF agent (Figure 1). However, less than half of the caretakers perceived the PSF unit as being accessible (Table 2).

Health agents are required, by the PSF, to make at least one visit to each home in their coverage area per month. Although a majority of caretakers reported an agent home visit at least once per month for all medical and preventative care, about a quarter of households in the Vespasiano PSF coverage area were not receiving an agent home visit once per month (Table 2). Other data from this study suggest monthly household visits by the agent were feasible, because the number of registered families assigned to each agent in Vespasiano ranged from 108 to 260 (mean 176; median 174), and the number of household visits conducted per day ranged from 5

TABLE 1. Characteristics of frequent users of the Family Health Program (caretakers of children under age 5 and covered by program services), Vespasiano, Minas Gerais, Brazil, 2009a

\begin{tabular}{lrc}
\hline \multicolumn{1}{c}{ Characteristic } & No. & $\%$ \\
\hline Age (mean $\left.\pm \mathrm{SE}^{\mathrm{b}}\right): 34 \pm 0.73(n=253)$ & & \\
Education level $(n=253)$ & & \\
Never attended school / some primary school & 110 & 43.5 \\
Completed primary school & 76 & 30.0 \\
Completed secondary school or more & 67 & 26.5 \\
Gender $(n=253)$ & & \\
Female & 238 & 94.1 \\
Marital status ( $n=253)$ & & \\
Never married & 37 & 14.6 \\
Married & 104 & 41.1 \\
Living with partner (not married) & 85 & 33.6 \\
Separated, divorced, or widowed & 27 & 10.7 \\
Relation to child ( $n=162)$ & & \\
Mother & 110 & 67.9 \\
Grandmother & 30 & 18.5 \\
Other & 22 & 13.6 \\
Employment $(n=247)$ & & \\
Regularly employed & 200 & 81.0 \\
Freelance work & 26 & 10.5 \\
Unemployed & 3 & 1.2 \\
Did not know or refused to answer & 18 & 7.3 \\
\hline
\end{tabular}

a Sample numbers differ due to variance in response rates across variable categories.

b SE: standard error.

c Examples of other relationships to child: babysitter, father, and grandfather.

FIGURE 1. Proportion of Family Health Program (PSF) users (caretakers of children under age 5 and covered by the program) satisfied with PSF agents $(n=219)$ and PSF units $(n=248)$, Vespasiano, Minas Gerais, Brazil, 2009

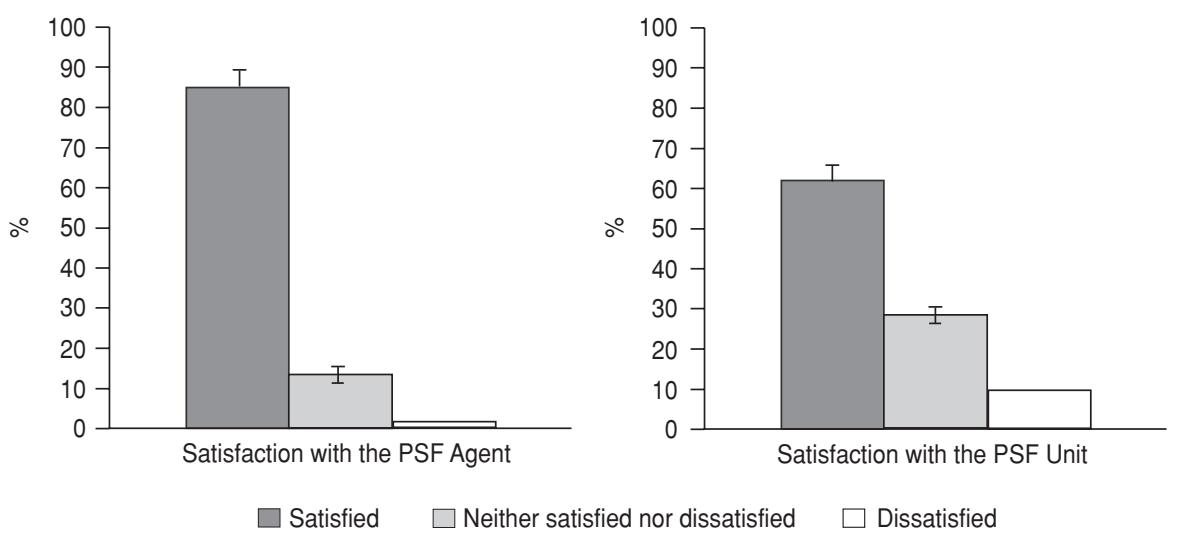

Error bars represent $95 \%$ confidence intervals.

to 23 (mean 12; median 11). Assuming 20 working days per month, and the upper range limit of assigned families (260), the authors estimated that an agent would have to make 13 visits per day in order to visit all of his/her clients at least once per month. Because the median number of daily visits reported by the agents was close to 13 visits per day, monthly agent visits appeared feasible.

To determine factors affecting caretakers' perceived satisfaction with both the PSF unit and the PSF community health agents, relationships between programmatic variables were explored through multivariate logistic models (Table 3). Frequency of agent home visits and user perceptions about PSF unit accessibility were considered as separate exposure variables. The models were adjusted for age, education, self-reported income, and number of household children younger than age 5 . None of these variables were significantly associated 
TABLE 2. Perspectives of Family Health Program (PSF) users (caretakers of children under age 5 and covered by the program) on PSF unit accessibility, frequency of PSF agent home visits for preventative and medical care, knowledge of rotavirus vaccine and its purpose, and child eligibility ${ }^{\mathrm{a}}$ for and coverage by rotavirus vaccination, Vespasiano, Minas Gerais, Brazil, 2009b,c

\begin{tabular}{|c|c|c|}
\hline Variable & No. & $\%$ \\
\hline \multicolumn{3}{|l|}{ Accessibility of PSF unit $(n=242)$} \\
\hline Yes & 110 & 45.5 \\
\hline Sometimes & 82 & 33.9 \\
\hline No & 40 & 16.5 \\
\hline Don't know & 10 & 4.1 \\
\hline \multicolumn{3}{|l|}{ Frequency of PSF agent home visits $(n=241)$} \\
\hline More than once per month & 62 & 25.7 \\
\hline Once per month & 109 & 45.2 \\
\hline Less than once per month & 33 & 13.7 \\
\hline Rarely or never & 37 & 15.4 \\
\hline \multicolumn{3}{|c|}{ Caretaker knowledge of rotavirus vaccine and its purpose $(n=223)$} \\
\hline Yes & 17 & 7.6 \\
\hline \multicolumn{3}{|c|}{ Children eligible for rotavirus vaccination $?^{\mathrm{a}}(n=139)$} \\
\hline Yes & 100 & 71.9 \\
\hline \multicolumn{3}{|l|}{ Rotavirus vaccination coverage $(n=100)$} \\
\hline 2 doses (full coverage) & 77 & 77.0 \\
\hline 1 dose & 7 & 7.0 \\
\hline 0 doses & 16 & 16.0 \\
\hline
\end{tabular}

with the outcome (data not shown). Interaction by perceived access to the PSF unit was also not statistically significant. Data suggested that caretakers who reported receiving a home visit from their community agent at least once per month were significantly more likely to be satisfied with services provided by their agent (Table 3, Model 1) and at the unit (Table 3, Model 2) than those who reported receiving a home visit less than once per month. Similarly, data suggested that those who perceived the PSF unit as being "accessible" or "sometimes accessible" were significantly more likely to be satisfied with services provided by their agent (Table 3, Model 1) and at their unit (Table 3, Model 2) than those who perceived the unit as inaccessible. In Model 2, the 95\% confidence interval (CI) around the OR for perceived "access to PSF" may have been wide because of the small sample of individuals who were satisfied with the PSF unit but perceived it as being inaccessible. These findings suggest the importance of both the frequency of the agent home visits and user-perceived access to PSF services in determining user satisfaction levels with the PSF overall.

The results indicated that the odds of perceiving the PSF unit as either "accessible" or "sometimes accessible" were 5.25 times higher (95\% CI: 2.00-13.76), after adjusting for age, income, education, and number of children under age 5 in the household, among those who reported that their health agent made one or more home visits per month, compared to those who reported receiving a home visit less than once per month (data not shown). This finding suggests that the frequency of health agent home visits was related to both perceived access to the PSF unit and satisfaction with the PSF unit and agent.

\section{User perceptions of PSF diarrhea care and knowledge of the rotavirus vaccine and its coverage rate}

To understand the community's perceptions of PSF services for child diarrhea, the investigators collected information about caretakers' use, experience, and evaluation of the PSF for child diarrhea as well as their knowledge of the rotavirus vaccine and its purpose. The two-week period prevalence of household-reported diarrhea in children 5 years and younger in Vespasiano was $8.0 \%$ during the months of June, July, and August 2009. Fifty-nine out of 252 caretakers $(23.6 \%)$ reported ever receiving care for their child's diarrhea at the

TABLE 3. Multivariate logistic modeling estimates on satisfaction of Family Health Program (PSF) users (caretakers of children under age 5 and covered by the program) with PSF agents and units, adjusted for age, education, monthly income, and number of household children under age 5, Vespasiano, Minas Gerais, Brazil, 2009

\begin{tabular}{|c|c|c|c|c|c|c|c|}
\hline \multirow[b]{2}{*}{ Model } & \multirow[b]{2}{*}{ Variable } & \multicolumn{3}{|c|}{ Unadjusted } & \multicolumn{3}{|c|}{ Adjusted } \\
\hline & & $\mathrm{OR}^{\mathrm{a}}$ & $95 \% \mathrm{Cl}^{\mathrm{b}}$ & $P$ & OR & $95 \% \mathrm{Cl}$ & $P$ \\
\hline \multirow[t]{6}{*}{ 1. Satisfaction with PSF agents } & Agent home visit frequency & & & & & & \\
\hline & Once per month or more & 5.59 & $2.65-11.80$ & $<0.0001$ & 3.67 & $1.47-9.15$ & 0.0053 \\
\hline & Less than once per month & $1.00^{c}$ & & & $1.00^{c}$ & & \\
\hline & Access to PSF unit & & & & & & \\
\hline & Yes or sometimes & 3.97 & $1.67-9.44$ & 0.0018 & 4.47 & $1.51-13.21$ & 0.0067 \\
\hline & No & $1.00^{\mathrm{C}}$ & & & $1.00^{\mathrm{C}}$ & & \\
\hline \multirow[t]{5}{*}{ 2. Satisfaction with PSF units } & Agent home visit frequency & & & & & & \\
\hline & Once per month or more & 3.85 & $2.32-6.62$ & $<0.0001$ & 4.04 & $2.03-8.05$ & $<0.0001$ \\
\hline & Less than once per month & $1.00^{c}$ & & & $1.00^{\mathrm{c}}$ & & \\
\hline & Access to PSF unit & & & & & & \\
\hline & $\begin{array}{l}\text { Yes or sometimes } \\
\text { No }\end{array}$ & $\begin{array}{r}23.90 \\
1.00^{c}\end{array}$ & $8.87-64.43$ & $<0.0001$ & $\begin{array}{r}28.65 \\
1.00^{c}\end{array}$ & 8.84-92.87 & $<0.0001$ \\
\hline
\end{tabular}

a OR: odds ratio.

${ }^{\mathrm{b}} \mathrm{Cl}$ : confidence interval.

c Reference variable. 
PSF unit, of which 15 (25.4\%) considered the care to be excellent or very good. Only $44(17.5 \%)$ of caretakers reported having ever received advice for child diarrhea from a PSF agent, of which 21 $(47.7 \%)$ ranked the advice as excellent or very good. Only $23(9.1 \%)$ of caretakers had ever received written educational materials about child diarrhea from the PSF, and only $5(2.0 \%)$ indicated they had ever participated in PSF educational activities pertaining to child diarrhea. Caretakers who reported that their PSF agent made at least one home visit per month were less likely to have received care for child diarrhea at the PSF unit (OR: $0.41 ; 95 \%$ CI: $0.23-0.73$ ) and more likely to have received care for child diarrhea from a PSF agent (OR: 2.36; 95\% CI: 1.05-5.28). These results indicate that few caretakers in the Vespasiano community utilized the PSF for child diarrhea care or prevention activities, yet emphasize the importance of the PSF agent home visits in the utilization of PSF diarrhea care. In addition, although the data suggest that caretakers had a low level of knowledge about the rotavirus vaccine (Table 2), the rotavirus coverage rate was $77.0 \%$ for eligible children.

\section{DISCUSSION}

The goal of this population-level study was to assess factors that influence the satisfaction of users (primary caretakers of children younger than 5 years) with PSF agents and units in Vespasiano, Minas Gerais, Brazil. Similar to other studies $(17,18)$, the results indicated that the majority of caregivers were satisfied with both their PSF unit and their PSF agent. Overall, caretakers were more frequently satisfied with their PSF agent than with their PSF unit, perhaps due to more frequent interactions with the agent compared to the unit (data not collected). Caretakers also may have received more personalized attention from their PSF agent than from their PSF unit, where they may have waited in lengthy lines, experienced a lack of doctors, and had difficulty scheduling appointments.

The majority of caretakers received at least one monthly home visit. The frequency of health agent home visits was positively and significantly associated with caretaker satisfaction with both the PSF agent and the PSF unit. Similar results were found in a study in Teresópolis, Rio de Janeiro State, in which PSF patients with a low frequency of home visits had significantly lower access to medicine delivery, were more likely to not remember their doctor's name, and were less likely to report that the PSF schedules their clinical appointments (17). In the broader patient satisfaction literature, patient-provider relationships were predictors of patient satisfaction (16, 25-28). The authors of the current study hypothesized that the frequency of agent home visits is a proxy for the type of relationship a caregiver has with their agent. This would suggest that the monthly agent home visit-one of the key elements of PSF servicesaffected the level of user satisfaction not only with the agent but also with the PSF unit overall. Perceived access to the unit was positively associated with caretakers' satisfaction with both their PSF agent and their PSF unit. The study also found that those who reported that their agent made one or more home visits per month were more likely to perceive the PSF unit as being "accessible" (or "sometimes accessible"). Universal access to health care is one of the founding pillars of Brazil's SUS (29), so PSF users expect their health care services to be easily accessible. Even if users are provided sufficient and appropriate care from the PSF doctors, nurses, and agents, the authors propose that negative perceptions about access will decrease overall user satisfaction with the program, as suggested in Andersen's behavioral model of health services (30).

The authors of the current study 1) suggest that caretakers who receive at least one agent home visit per month have a better relationship with their agent, perceive the PSF unit as being accessible, and are more satisfied with both their PSF agent and their PSF unit (Figure 2), and 2) propose that users' perceived level of access to the PSF can be improved by ensuring that all households receive at least one home visit per month from a PSF agent, which should in turn improve caretakers' perceptions of the PSF and increase their overall satisfaction. However, because the study was cross-sectional, the temporality of these relationships could not be established by the study model.

Although the children's caretakers rarely received child diarrhea care and prevention services from either their PSF unit or their PSF health agent, any use of these services was significantly associated with the frequency of health agent home visits. In addition, caretakers who reported that their agent made at least one home visit per month were less likely to have received care for child diarrhea at the PSF unit and were significantly more likely to have received care for child diarrhea from an agent. Therefore, the authors hypothesized that 1) caretakers who received regular household visits were also receiving diarrhea care from their agents, and those who did not receive regular household visits had to go to the PSF unit to get diarrhea care, and 2) in general, the low utilization of the PSF for diarrhea care and prevention services may be a result of the fact that caretakers may view most child diarrhea as a condition that only required home treatment or would simply run its course $(31,32)$.

This study had several strengths. For example, because the survey pool (primary caretakers of children in Vespasiano who were 5 years or younger

FIGURE 2. Pathway for increased user satisfaction with Family Health Program (PSF), including significant associated factors (in boxes) and their relationships (of unknown directionality), and their correlation with age, income, and education, Vespasiano, Minas Gerais, Brazil, 2009

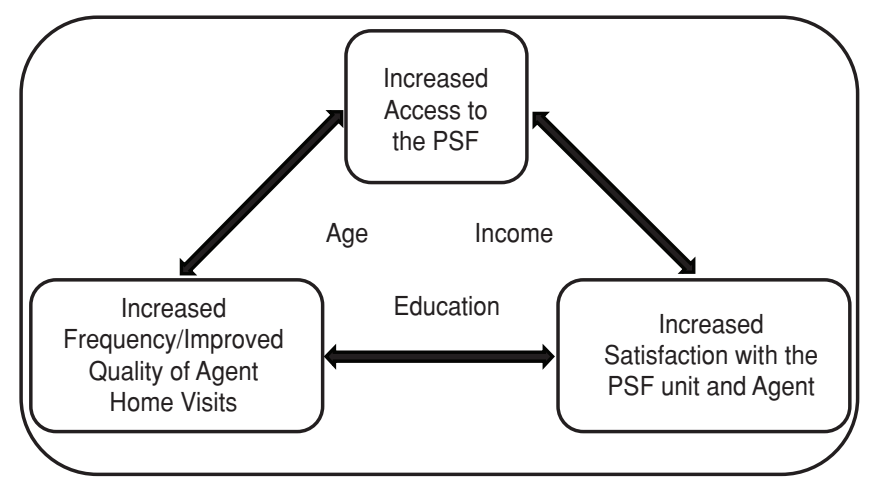


and covered by the PSF) was randomly sampled, the resulting data were generalizable to the entire population of PSF caretakers throughout the municipality. Furthermore, the sampling frame was stratified by the PSF unit, which provided an even distribution of selected individuals according to the population size of the unit coverage area while capturing innate differences between those areas. In addition, the multivariate models in the data analysis allowed for the inclusion of both demographic and programmatic variables in determining significant relationships with caretaker satisfaction.

This study also had several limitations, including the requirements that the PSF health agents accompany the researchers during all household visits, which may have been a source of respondent bias (even though the agents were not physically present during the surveys). In addition, all responses (except those regarding rotavirus vaccination status) were based on self-reports-a potential source of information bias that may have affected the study's internal validity. The lack of an operational definition of "satisfaction" with an individual's health care or health care system in the public health literature also proved challenging in the current study, as it has in the field in general $(2,16,25)$, in terms of measuring user perceptions and satisfaction. Finally, the current study results are specific to the Vespasiano municipality and therefore may only be generalizable to other Brazilian cities of similar size and socioeconomic status. Despite this last limitation, the main conclusions may still apply to PSF units nationwide as well as similar national health systems throughout Latin America.

The multivariate approach used in this study, which uses population-level data to study health system user satisfaction, generated a novel pathway model for perceived user access, health agent home visits, and demographic variables, and may contribute to the study of user perceptions in health systems research. The current results highlight the importance of health agent home visits and perceived accessibility to program services for caretaker satisfaction with Brazil's Family Health Program and may also be useful in measuring other aspects of the national health system. More generally, they provide evidence that frequent contact between users and their health system may improve overall user satisfaction. Future research on the PSF and other health systems should measure the quality of health agent home visits and apply the currently proposed model on various community health priorities (e.g., nutrition, vaccines, and chronic diseases). As the PSF expands its coverage and scope (e.g., establishing links to other levels of care (8)), the current model may help inform future decisions in PSF planning to ensure that home visits and the agent-community relationship are emphasized in training, funding, and practice. The authors suggest that developing better health care delivery and agent-community relationships (e.g., by improving the frequency and quality of visits) may provide a tangible pathway to increasing perceived accessibility to and satisfaction with the health care system in Brazil and other countries.

Acknowledgments. JSL was supported in part by funds from the Emory University Global Health Institute, through U.S. National Institutes of Health (NIH)-National Institute of Allergy and Infectious Diseases (NIAID) grant 1K01AI087724-01, and U.S. Department of Agriculture (USDA)-National Institute of Food and Agriculture (NIFA) grant 2010-85212-20608. KEM was supported in part by the Eugene J. Gangarosa Fund, the Anne E. and William A. Foege Global Health Fund, the O.C. Hubert Charitable Trust, the RSPH [Rollins School of Public Health] Student Initiative Fund, and the NIH Global Frameworks Grant (2007-2010). The authors thank Bernardo Patrus and Priscila Said Saleme of the Faculdade da Saúde e Ecologia Humana (FASEH), for their input during data collection and during manuscript development; Eric Mintz and Jay McAuliffe, for their valuable input throughout the project; Hérica Soraya Albano, Vespasiano's Municipal Secretary of Health; Assuero Rodrigues da Silva, director of the FASEH; and the Family Health Program (PSF) professionals and community members who participated in this work.

\section{REFERENCES}

1. Alva S, Kleinau E, Pomeroy A, Rown K. Measuring the impact of health systems strengthening: a review of the literature. Washington: U.S Agency for International Development; 2009.

2. Bleich SN, Ozaltin E, Murray CK. How does satisfaction with the health-care system relate to patient experience? Bull World Health Organ. 2009;87(4):271-8.

3. Rosenthal GE, Shannon SE. The use of patient perceptions in the evaluation of healthcare delivery systems. Med Care. 1997;35(11 Suppl):NS58-68.

4. Donabedian A. Explorations in quality assessment and monitoring. Vol 1. The definition of quality and approaches to its assessment. Ann Arbor, MI: Health Administration Press; 1980.

5. Nelson EC, Hays RD, Larson C, Batalden PB. The patient judgment system: reliability and validity. QRB Qual Rev Bull. 1989;15(6):185-91.
6. Nelson EC, Larson CO, Hays RD, Nelson SA, Ward D, Batalden PB. The physician and employee judgment system: reliability and validity of a hospital quality measurement method. QRB Qual Rev Bull. 1992;18(9):284-92.

7. Cleary PD, Edgman-Levitan S, McMullen W, Delbanco TL. The relationship between reported problems and patient summary evaluations of hospital care. QRB Qual Rev Bull. 1992;18(2):53-9.

8. Paim J, Travassos C, Almeida C, Bahia L, Macinko J. The Brazilian health system: history, advances, and challenges. Lancet. 2011;377(9779):1778-97.

9. Ministério da Saúde (BR). Atenção básica e a saúde da família [Internet]. Brasília: MS; c2011. Available from: http://dab.saude.gov. br/atencaobasica.php. Accessed 30 June 2010.

10. Ministério da Saúde (BR). Os números da saúde da família [Internet]. Brasília: MS; c2011.
Available from: http://dab.saude.gov.br/ab numeros.php\#numeros. Accessed 30 June 2010. 11. United Nations Children's Fund. Countdown to 2015: maternal, newborn, and child survival. Tracking progress in maternal, newborn \& child survival. The 2008 Report. New York: UNICEF; 2008.

12. Aquino R, de Oliveira NF, Barreto ML. Impact of the Family Health Program on infant mortality in Brazilian Municipalities. Am J Public Health. 2009;99(1):87-93.

13. Macinko J, Guanais FC, de Fátima $M$, de Souza M. Evaluation of the impact of the Family Health Program on infant mortality in Brazil, 1990-2002. J Epidemiol Community Health. 2006;60(1):13-9.

14. Macinko J, Marinho de Souza Mde F, Guanais FC, da Silva Simões CC. Going to scale with community-based primary care: an analysis of the Family Health Program and infant 
mortality in Brazil, 1999-2004. Soc Sci Med. 2007;65(10):2070-80.

15. Carr-Hill RA. The measurement of patient satisfaction. J Public Health Med. 1992 Sep;14(3):236-49.

16. Hudak PL, Wright JG. The characteristics of patient satisfaction measures. Spine (Phila Pa 1976). 2000;25(24):3167-77.

17. Ribeiro JM, de Siqueira SA, Pinto LF. Avaliação da atenção à saúde da criança $(0-5$ anos) no PSF de Teresópolis (RJ) segundo a percepção dos usuários. Cien Saude Colet. 2010;15(2):517-27.

18. Ronzani TM, Silva Cde M. O Programa Saúde da Família segundo profissionais de saúde, gestores e usuários. Cien Saude Colet. 2008;13(1):23-34.

19. Assembleia Legislativa de Minas Gerais (BR). Cobertura do PSF em Minas Gerais alcança $96 \%$ dos municípios [Internet]. Exibição de Notícia. Belo Horizonte, MG: ALMG; 2007. Available from: http://www.diamantina.mg.gov.br/003/00301009.asp?ttCD CHAVE $=63175$. Accessed 11 January 2012.

20. ORC Macro. Model "A" Questionnaire with Commentary for High Contraceptive Prevalence Countries. Measure DHS+ Basic Documentation No. 1. Calverton, MD: ORC Macro; 2001. Available from: http://www. measuredhs.com/pubs/pdf/DHSQ4/DHSIV-Model-A.pdf.pdf
21. Ministério da Saúde, Secretaria de Vigilância em Saúde, Departamento de Vigilância Epidemiológica (BR). Doença diarréica por rotavírus: vigilância epidemiológica e prevenção pela Vacina Oral de Rotavírus Humano - VORH. Brasília: MS; 2006. p. 36. Available from: http://portal.saude.gov.br/portal/ arquivos/pdf/informe_rotavirus_02_03_2006. pdf

22. Dorofeev S, Grant P. Statistics for real life sample surveys. Cambridge: University Press; 2006.

23. Kleinbaum DG, Klein M. Logistic regression: a self-learning text. 2nd ed. New York: Springer; 2005.

24. OANDA Corporation. Currency Converter [Internet]. New York: OANDA; c1996-2011. Available from: http://www.oanda.com/ currency/converter/. Accessed 30 June 2010.

25. Crow R, Gage H, Hampson S, Hart J, Kimber A, Storey L, et al. The measurement of satisfaction with healthcare: implications for practice from a systematic review of the literature. Health Technol Assess. 2002;6(32):1-244.

26. Atkinson S, Haran D. Individual and district scale determinants of users' satisfaction with primary health care in developing countries. Soc Sci Med. 2005;60(3):501-13.

27. Jackson JL, Chamberlin J, Kroenke K. Predictors of patient satisfaction. Soc Sci Med. 2001;52(4):609-20.
28. Nguyen Thi PL, Briançon $\mathrm{S}$, Empereur $\mathrm{F}$, Guillemin F. Factors determining inpatient satisfaction with care. Soc Sci Med. 2002;54(4):493-504.

29. Ministério da Saúde (BR). Sistema Único de Saúde [Internet]. Brasília: MS; c2011. Available from: http://portal.saude.gov.br/ portal/saude / cidadao/area.cfm?id area $=1395$. Accessed 10 June 2010.

30. Andersen RM. Revisiting the behavioral model and access to medical care: does it matter? J Health Soc Behav. 1995;36(1):1-10.

31. Granich R, Cantwell MF, Long K, Maldonado Y, Parsonnet J. Patterns of health seeking behavior during episodes of childhood diarrhea: a study of Tzotzil-speaking Mayans in the highlands of Chiapas, Mexico. Soc Sci Med. 1999;48(4):489-95.

32. de Zoysa I, Carson D, Feachem R, Kirkwood B, Lindsay-Smith E, Loewenson R. Perceptions of childhood diarrhoea and its treatment in rural Zimbabwe. Soc Sci Med. 1984;19(7): $727-34$.

Manuscript received on 15 March 2011. Revised version accepted for publication on 15 August 2011.

RESUMEN Objetivo. Evaluar los factores que influyen en las perspectivas sobre el Programa de Salud Familiar (PSF) del Brasil, mediante el análisis de la satisfacción de los usuarios frecuentes del PSF (cuidadores primarios de niños menores de 5 años) con las unidades y los agentes de salud comunitarios que efectúan las visitas a domicilio, y de la percepción de dichos usuarios respecto de la accesibilidad a la unidad del PSF en Vespasiano, Minas Gerais.

\section{Satisfacción de los usuarios con el Programa de Salud Familiar en Vespasiano, Minas Gerais, Brasil}

Palabras clave
Métodos. Se recopilaron datos mediante encuestas transversales de hogares para determinar los factores programáticos y demográficos que afectaban la satisfacción de los usuarios con el PSF. Para estimar la satisfacción de los usuarios con las unidades y los agentes de salud del PSF y su percepción sobre el acceso a los servicios prestados por la unidad del PSF se usó un modelo logístico multifactorial. Para calcular las diferencias estadísticas se usaron las pruebas de ji al cuadrado y análisis de la varianza (ANOVA).

Resultados. La mayoría de los cuidadores estuvieron satisfechos tanto con su unidad del PSF como con su agente de salud comunitario del programa, de quien habían recibido al menos una visita a domicilio mensual. La satisfacción con este y con la unidad se asoció positivamente con la percepción de acceso a la unidad y con la frecuencia de las visitas a domicilio del agente. Los cuidadores que informaron que su agente del PSF hizo una o más visitas al domicilio por mes presentaron mayores probabilidades de considerar a la unidad del PSF como "accesible" (o "a veces accesible").

Conclusiones. Los datos actuales son indicadores importantes del estado de salud de la población en Minas Gerais, Brasil, y sugieren que la satisfacción de los usuarios con el PSF y su percepción acerca de la accesibilidad a este pueden mejorarse si se garantiza que todos los hogares reciban al menos una visita a domicilio mensual del agente de salud. Estos resultados podrían aplicarse a otras zonas del Brasil o de América Latina para comprender mejor la percepción de los usuarios sobre los sistemas de salud.

Evaluación de programas y proyectos de salud; programas nacionales de salud; bienestar del niño; satisfacción del paciente; diarrea infantil; vacunas contra rotavirus; Brasil. 